REVIEW

\title{
Knowledge Management Implementation and the Tools Utilized in Healthcare for Evidence-Based Decision Making: A Systematic Review
}

\author{
Leila Shahmoradi ${ }^{1}$, Reza Safadari ${ }^{2}$, Worku Jimma ${ }^{3,4^{*}}$
}

\footnotetext{
OPEN ACCESS

Citation: Leila Shahmoradi, Reza Safadari, Worku Jimma. Knowledge Management Implementation and the Tools Utilized in Healthcare for Evidence-Based Decision Making: A Systematic Review. J Health Sci 2017;27(5):541. doi: http://dx.doi.org/10.4314/ejhs.v27i5.13

Received: January 10, 2017

Accepted: January 18, 2017

Published: September 1, 2017 Copyright: (C) 2017 Leila Shahmoradi, et $a l$. This is an open access article distributed under the terms of the Creative Commons Attribution License, which permits unrestricted use, distribution, and reproduction in any medium, provided the original author and source are credited

Funding: Nil

Competing Interests: The authors declare that this manuscript was approved by all authors in its form and that no competing interest exists.

Affiliation and Correspondence:

${ }^{1}$ Department of Health Information Management, School of Allied Medical Sciences, Tehran University of Medical Sciences, Tehran, Iran

${ }^{2}$ Department of Health Information Management, School of Allied Medical Sciences, Tehran University of Medical Sciences, Tehran, Iran

${ }^{3}$ Department of Information Science, College of Natural Sciences,

Jimma University, Jimma, Ethiopia

${ }^{4}$ Department of Health Information Management, School of Allied Medical Sciences, Tehran University of Medical Sciences, International Campus (TUMS-IC), Tehran, Iran.

"Email: worku.jimma@yahoo.com
}

\begin{abstract}
BACKGROUND: Healthcare is a knowledge driven process and thus knowledge management and the tools to manage knowledge in healthcare sector are gaining attention. The aim of this systematic review is to investigate knowledge management implementation and knowledge management tools used in healthcare for informed decision making.

METHODS: Three databases, two journals websites and Google Scholar were used as sources for the review. The key terms used to search relevant articles include: "Healthcare and Knowledge Management"; "Knowledge Management Tools in Healthcare" and "Community of Practices in healthcare".

RESULTS: It was found that utilization of knowledge management in healthcare is encouraging. There exist numbers of opportunities for knowledge management implementation, though there are some barriers as well. Some of the opportunities that can transform healthcare are advances in health information and communication technology, clinical decision support systems, electronic health record systems, communities of practice and advanced care planning.

CONCLUSION: Providing the right knowledge at the right time, i.e., at the point of decision making by implementing knowledge management in healthcare is paramount. To do so, it is very important to use appropriate tools for knowledge management and user-friendly system because it can significantly improve the quality and safety of care provided for patients both at hospital and home settings. KEYWORDS: Knowledge management, tools, evidence-based medical practice, healthcare, informed decision making
\end{abstract}

\section{INTRODUCTION}

Healthcare is a knowledge driven process and thus knowledge management (KM) and the tools to manage knowledge in health sector are gaining attention (1). According to Hongsermeier et al (2), technology plays vital role in $\mathrm{KM}$ in facilitating knowledge flow

DOI: http://dx.doi.org/10.4314/ejhs.v27i5.13 
through its life cycle, being realized by the implementation of knowledge management system (KMS). Information technology (IT) provides a technical foundation that facilitates KMS implementation. It also provides a means by which a strong theoretical foundation for KM can be implemented because it is used in all the life cycle stages of KM. IT is highly required in the stages of socialization-externalization-combinationinternalization(SECI) model by Nonaka and Takeuchi (3). This model cannot be precluded in KM processes. Some of the technologies that can be used for KM during knowledge transformation, i.e., the conversion of one form of knowledge to the other form of knowledge in the model include electronic meeting systems, Internet, group collaboration system to convert tacit knowledge into tacit knowledge. For conversion of tacit knowledge into explicit knowledge, knowledge database and document/content management systems can be used. To convert explicit knowledge into explicit knowledge, data warehousing and information system are some of the technologies which can be used and for conversion of explicit knowledge into tacit knowledge, tools such as decision support systems and electronic performance support system are used (4). Knowledge transfer and sharing has three components; namely people, process and technology. However, due attention should be given to the right balance of the efforts of these three components for successful KM implementation (5).

According to Butler and Murphy (6) and the references therein, mixed findings were reported on the successful application of IT for KM. The difficulty is on the use of management techniques, the concepts to design and develop KM tools, the availability of multiple KM technologies, as well as their applications and usage. There are numbers of IT artefacts known to support knowledge creation, storage, retrieval, transfer and application which include data management and learning tools; knowledge repositories; databases; electronic bulletin boards, etc. (6) and these KM technologies are important components of KMS in healthcare.
Healthcare sector relies heavily on knowledge in its daily activities, and mainly, the delivery of care depends upon the collaboration of various partners that should share knowledge in order to provide quality care for patients (7). For this purpose, medical knowledge should be made available and readily accessible to all in need of it, and thus, KM is a paramount important for collaboration and sharing of knowledge so that optimal outcomes of the healthcare service is realized (7). In general, there are numbers of advantages of implementing $\mathrm{KM}$ in the healthcare sector.

Another important aspect that needs to be considered with KM implementation in healthcare is what is known as evidence-based medical practices (EBMP), i.e., the integration of research evidence, clinical expertise and patient preferences and values in clinical decision making (1), which is known to influence decision making throughout healthcare delivery processes. In this respect, the big challenge remains in how to fit patients' tacit knowledge into this practice. The rationale for EBMP is derived from the need of care providers to be more accountable for their patients (8). Accordingly, managing both tacit and explicit knowledge has a great role to play for EMBP to be successful.

The role of $\mathrm{KM}$ in decision making to improve the quality of healthcare delivery is to do with the adoption of the right strategy of managing knowledge for informed clinical decision making (8). This work was intended to answer the following key questions:

How is healthcare service delivery affected by the implementation of knowledge management with respect to informed decision making?

Which tools are currently used to manage knowledge in order to facilitate and improve healthcare services?

What are the challenges that limit $\mathrm{KM}$ implementation in healthcare?

The main aim of this review is thus to investigate knowledge management implementation and the tools used to manage knowledge in healthcare for evidence-based decision making and thereby improve quality of healthcare services. The best approach to address

DOI: http://dx.doi.org/10.4314/ejhs.v27i5.13 
the aim and answer the research questions is conducting a systematic review on the research works done so far in this area and under different settings. Accordingly, the review was conducted by undertaking an extensive literature search and screening of research works conducted over a period of ten years (2005-2015).

The reviewed articles showed strong evidence that $\mathrm{KM}$ implementation in healthcare is encouraging, and there are numbers of KM tools available, which can impact decision making. It can be said that implementing KM in healthcare by seizing the available opportunities, such as advances in healthcare information and communication technology, clinical decision support systems, electronic health record systems, communities of practice and advanced care planning is the way forward to improve the quality of care for patients, which is the ultimate goal of healthcare.

\section{METHODS}

Sources of articles and the searching strategy: Electronic resources were identified from various sources. Accordingly, three databases; namely, PubMed Central, EBESCOhost and Health Technology Assessment (HTA); two open source journal websites; namely, Electronic Journal of Knowledge Management and Journal of Knowledge Management Research and Practices and also Google Scholar were used. Publications over the period of 2005-2015 in English language were selected for this work from the aforementioned sources. Google Scholar was used to include grey literature.

The key terms used as a search strategy were: "Knowledge Management in Health Care"; "Knowledge Sharing and Utilization"; "Knowledge Management Tools in Healthcare" and "Community of Practices in Healthcare". The key terms "Community of Practices in Healthcare" were included in the search strategy not to miss out fundamental articles because it is a practice, which is popular in healthcare sector for sharing and managing knowledge. As an example, for PubMed Central database, the detailed search with a key term "Knowledge Management in Health Care" was done as follows: (("knowledge

management"[MeSH

Terms] OR

("knowledge"[All Fields]

AND "management"[All

Fields]) OR "knowledge management"[All Fields])

AND ("In Health"[Journal]

OR ("in"[All Fields] AND

"health"[All Fields]) OR

"in health"[All Fields])

AND care [All Fields])

For the two open source journals; namely, Electronic Journal of Knowledge Management and Journal of Knowledge Management Research and Practices, hand searching was employed by accessing the archived journal issues from their respective official websites. Accordingly, articles on healthcare were downloaded selectively because these journals address $\mathrm{KM}$ in various sectors besides healthcare.

The steps involved to identify relevant eresources for the systematic review were searching, screening, eligibility and inclusion. Searching was conducted using the key terms listed above. Then, the records were thoroughly screened to eliminate non-relevant records by reading the titles, abstracts and finally the full texts, based on the set inclusion/exclusion criteria. Duplicates were eliminated by using EndNote software. In order to eliminate bias, screening of the abstract and full text was done by two researchers separately and the results were compared. After the screening activity was completed, the selected articles were checked for completeness and retained for the review work. Finally, 44 articles were found eligible for the present review with the agreement of both researchers, and then information abstraction from the findings of the selected articles was performed to produce this systematic review article. To this end, the analysis method used was mainly synthesizing. The abstracted information was categorized based on the themes identified to be addressed, namely implementation of $\mathrm{KM}$ in healthcare, KM tools in healthcare, opportunities and barriers of $\mathrm{KM}$ implementation and tools in healthcare. Since the aim was not to determine the 


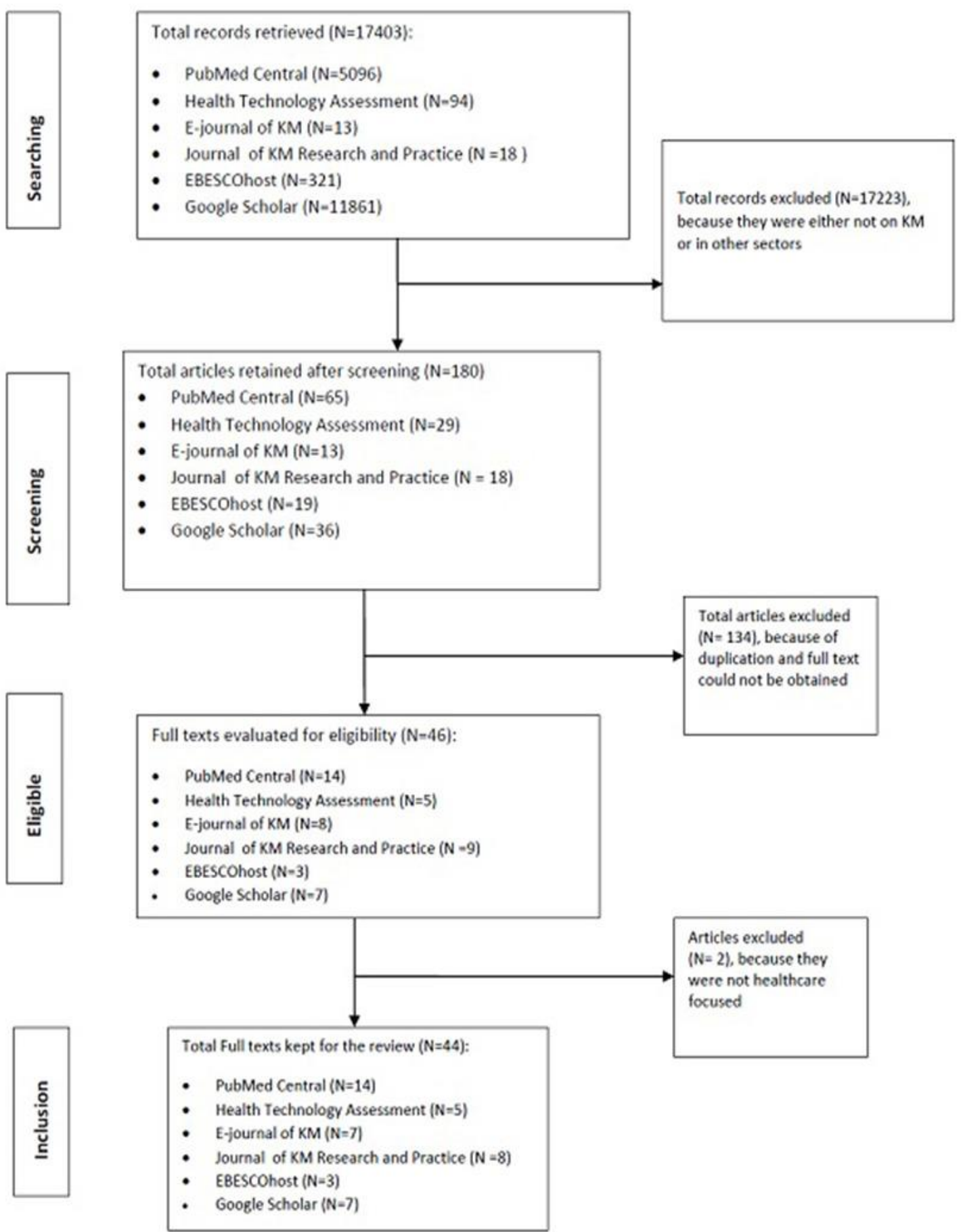

Fig. 1: The steps involved to identify relevant e-resources for the systematic review.

DOI: http://dx.doi.org/10.4314/ejhs.v27i5.13 
extent of the effect of utilizing KM tools or its implementation, rather to describe a body of literature systematically, no risk of bias assessment was done. Thus, qualitative appraisal would have made no difference even if it was done. PRISMA checklist was employed as a basis to produce this systematic review work. The steps followed for the search is depicted in Figure 1.

Inclusion and exclusion criteria: Articles published over the period of ten years (2005-2015) on $\mathrm{KM}$ in healthcare, and the tools utilized were considered for this systematic review. Publications before 2004 and after 2015 were excluded by limiting the search to ten years. Besides, articles in languages other than English were excluded. The inclusion and exclusion involved two stages. The first is reading the abstract and retaining or eliminating the papers based on their relevance to the key questions this review work intended to answer. The second stage is reading the full text of the retained articles and articles that were not in line with the review work at hand were excluded, such as if the publication is not in healthcare sector. Moreover, research works done in high, middle and low income countries were sought to be included because no exclusion criteria was set to leave out a work in any setting or country that the key terms we used returned. In general, articles on KM were included if they had an impact on the quality of healthcare services delivery, including knowledge sharing of pharmaceutical companies, Hospital-in-the-Home Unit, home health rehabilitation via virtual network for communication, etc.

\section{REVIEW FINDINGS}

The search activity returned a total of 17403 records of which 17223 were excluded after reading just the titles because they were not on $\mathrm{KM}$ and/or on KM of other sectors. After reading the abstracts, 134 articles were excluded of the 180 retained records due to duplication and also since full texts could not be obtained for some. Attempts, like contacting the authors and searching in other sites such as, ResearchGate were done to acquire full texts of the articles that the search returned only the abstracts. Unfortunately, our effort was unsuccessful and these articles were finally excluded. The remaining 46 articles were further assessed for eligibility, and finally, 44 articles were included for this review work because two of the articles were not healthcare focused, even though there was a mention about healthcare. The steps followed to this end are depicted in Figure 1.

The findings are categorized under three main headings; namely: I) Implementation of knowledge management in healthcare; II) Knowledge management tools in healthcare; and III) Opportunities and barriers of $\mathrm{KM}$ implementation and tools in healthcare whereby main factors are presented as sub-headings under these headings. Accordingly, under the first heading, knowledge sharing; virtual communication and knowledge flow as well as evidence-based decision making to improve quality of patient care are the themes identified, as these are the forms in which $\mathrm{KM}$ is used in healthcare. Under the last theme, opportunities such as advances in health information and communication technology; clinical decision support system; electronic health record systems; communities of practice; and advanced care planning are included. However, it should be noted that the themes identified are not mutually exclusive. For instance, knowledge implementation requires $\mathrm{KM}$ tools and evidencebased medical practice is impossible without $\mathrm{KM}$ implementation, especially sharing of knowledge. These themes are presented below.

\section{Implementation of knowledge management} in healthcare: $\mathrm{KM}$ has received attention in healthcare only recently due to the growing amount of data and information, and thus the concept of KM is beginning to emerge (9). Some of the reasons for KM use in healthcare, like in business sector, include prevention of possible knowledge loss due to retirement and staff turnover; gaining competitive advantage; continuous learning; prevention of knowledge diffusion and/or isolation of organization or department or individuals and the need of fulfilling users needs (9). The vital aspects of KM implementation include utilization, transfer and

DOI: http://dx.doi.org/10.4314/ejhs.v27i5.13 
translation of knowledge. Knowledge utilization is the process of converting knowledge, such as evidence-based guidelines to practices, whereas knowledge translation moves scientific knowledge from basic discovery to testing for technical efficiency and then to acceptability for adoption in practices, which indicates that this aspect of KM has two phases. The third important aspect of KM, knowledge transfer, is the diffusion of knowledge that is directed and managed by using various strategies $(10,11)$.

Knowledge transfer has three components; namely, people, process and technology. However, the right balance of these three components should be kept for its successful implementation (5). It should be noted that of these three components, the most important pillar for knowledge sharing process is people. The processes component provides support for $\mathrm{KM}$ implementation in general, and the technology component provides a knowledge portal linking people via different means such as e-mail and knowledge repository. Therefore, adoption of a good strategy is unquestionable for $\mathrm{KM}$ implementation in healthcare $(5,8)$. Under this section, factors such us knowledge sharing; virtual communication and knowledge flow; evidencebased decision making to improve quality of patient care are presented.

A. Knowledge sharing: Knowledge sharing is one of the fundamental steps in KM processes. Inter-organizational knowledge sharing system can serve as a strategic system for knowledge intensive sectors such as healthcare. The benefits of inter-organizational knowledge sharing were found to be enormous of which the top 20 benefits identified were related to individual benefits, knowledge sharing process, customer benefits, organizational benefits and sector benefits (12). Individual benefits include improved learning, decision making, problem solving, productivity and job satisfaction, whereas knowledge sharing process benefits are related to improved staff collaboration, faster information flow, information availability/accessibility, information quality, creation of new knowledge and social networking. Customer benefits include faster services, reduced error/quality problem and organizational benefits include saving time of organization, improved organization learning, reduced duplicated work and saving of staff time. Moreover, there are sector benefits, such as improvement of standardization (12-14). Another study conducted in multinational healthcare companies; namely, pharmaceutical companies in Greece (15) on stakeholders' assessment with co-workers and managers as participants explored knowledge and insights on what knowledge has been transferred and how. In another study, it was reported that African Medical and Research Foundation (AMREF), a leading knowledge hub in healthcare in Africa, has developed a KM strategy which focuses on creating, capturing and applying health knowledge. The huge knowledge produced by this foundation can be accessed online, and the stakeholders are provided with the right information at the right time. The platforms include website and intranet of AMREF, digital library, ART knowledge hub online platform and AMREF library e-bulletin (16).

B. Virtual communication and knowledge flow: Another setting whereby data and knowledge of medical interest can be stored, processed and become available for the stakeholders within the distributed system is known as Hospital-in-the Home Unit (HHU). There is a similar setting called home health rehabilitation via virtual network $(17,18)$. Such settings allow patients who are dispersed geographically to get the services they need via the virtual platform that offers communication and shared knowledge with physicians and other healthcare professionals. Diversity and intensity of knowledge flow among its stakeholders, also known as knowledge ecosystem, are the most important feature within virtual health network and help communities to evolve faster $(17,19)$, but the entire technology that supports the network should be user-friendly and must fit the healthcare process requirements in order to stimulate dialog among the ecosystem stakeholders. Moreover, such a network helps people with disabilities to achieve better quality of life as well as bring about healthcare services cost minimization by addressing the right problem in 
the right way $(17,18,20)$. Examples of such a network are a virtual hospital in Finland (ATULINE); the stroke center Enchede in the Netherlands and the SYSCO healthcare system in the USA (8).

ICT based services and systems such as smart home, which is a real-time continues activity being supported by ICT technology is new in healthcare (21). To nurture the networking or virtual setting technologies, such as telemedicine technology, HHU needs to provide and support exploratory activities and the exploitation of knowledge plays a major role in facilitating such technologies (19). This study revealed that there is an association between telemedicine technology and patient e-knowledge. Exploration of knowledge on the use of telemedicine technology is very important (22).

\section{Evidence-based decision making to improve quality of patient care: The Model of evidence-} based decision making has its origin in Canada, at the Department of Clinical Epidemiology and Biostatics, McMaster University in 1981. The rationale of such practices was mainly derived from the need of care providers to be more accountable for their patients (8). It plays a significant role in patient care such as enhancing quality of care, ensuring individual based on the most up-to-dated evidence, ensuring physicians to maximize the likelihood of positive outcomes as well as minimizing the existing gap between research and practice. Thus, it has influenced decision making and actions taken throughout healthcare industry for over two decades now $(8,23)$. The practice, according to these authors and the references therein, follow four steps: i) formulation of a clear clinical question related to patient problem; ii) a search in literature for relevant clinical practices; iii) the evaluation of the available evidence for its usability; and iv) implementation of the evidences in clinical practices. EBMP answers the "why-what-how" questions for healthcare leaders. These days, the "why" concepts of knowledge and evidence have received attention because of the increase in the number of the aging population, growing complexity of biomedical research, great advances in knowledge and technology research (23).
To promote the development of both local and global evidence-based decision making strategies, knowledge sharing is a major issue to be addressed and is at the crossroads of KM model in the $21^{\text {st }}$ century. Hence, in today's healthcare system, competency is essential at all levels, and as a result of the movement of EBMP, all health professionals can no longer be competent enough without knowing and learning continuously. The "what" level of competency requirement is the dimension of knowledge and types of evidences needed, such as storage media, accessibility, typology and hierarchy, whereas the "how" level is the implementation of the evidence (23). Therefore, resource for EBMP that continually search, appraise and summarize literature for physicians is highly needed. Automated semantic processing of text in the medical domain is another means that provides a unique opportunity to explore complex question-answering in the clinical medical domain as a systematic design to satisfy the need for information by practitioners who practice evidence based medicine (24), unlike the traditional medical knowledge, which is acquired either by studying written or published materials (25).

The finding of a research by Boateng (8) showed that medical doctors who were interviewed strongly agreed that EBMP is the best route to ensure effective healthcare delivery and believed in the involvement of patients in clinical decision making. Shared decision making could potentially improve healthcare delivery as it is about putting the patient at the center of healthcare (26). However, awareness creation in shared decision making in the case of sensitive decision i.e., a "no best choice" case is the most important step. In such a case, decision aide techniques and tools like pamphlets, videos and web-based tools should be used to outline the benefits and harms of the available options to the patient. Discussing the benefits and harms of each option, listening to patients' ideas, concerns and expectations about the options should be addressed well, and above, all it is very vital to help the patient in the process $(, 14,25,26)$. It is emphasized that collective consultation enabled by on-line platform could be seen as extreme application of the usual practice 
of patients to consult more than one doctor to get a second or even a third say regarding their conditions (25), and web-based tool for the purpose is seen as a positive step by both doctors and ICT researchers as it allows for patient involvement in decision making. This indicates that clear communication and active dissemination of evidence to all relevant stakeholders in easy-tounderstand formats are vital to increasing awareness, consideration, adoption and facilitating of its use (10).

The quality of healthcare delivery is highly determined by the adoption of the right strategy of $\mathrm{KM}$ for informed clinical decision making. When both explicit and tacit knowledge are used by both doctors and patients, EBMP flourishes. Moreover, $\mathrm{KM}$ policy is critical to well address the objective of EBMP terms, and the KM forms, strategies and practices to be adopted (8). The author opined that embracing EBMP strategy of KM in healthcare holds a great potential to improve healthcare delivery, especially in developing countries. A similar study by Clark et al (27) reported that high quality decision making with associated aspects such as informed consent, effective communication and patient environment are very important aspects of inserting and deactivation of electronic cardiac devices, which is a specific example of decision making.

Nowadays, substantial attention is given to EBMP and policy making to utilize research knowledge by healthcare system. Knowledge translation, a process which includes activities such as synthesis, dissemination, exchange and application of knowledge in order to improve healthcare services and products, is another aspect to be considered. This is seen from the perspective of decision makers or policy makers because its ultimate goal is to facilitate incorporation of research knowledge into program and policy development decision making (28). In Iran, a tool was developed for self-assessment of knowledge translation and the main knowledge translation facilitator, is reported to be the huge scientific publication in the health field (29). The authors suggested that to strengthen knowledge translation, both researchers and policy makers need to give attention at all levels. Moreover, it was emphasized that there is a need of network establishment, priority setting and building of trust among policy makers and researchers. Currently, biomedical discoveries emerge at increasing rate, but the translation into healthcare typically occurs because of lack of a sufficient system to identify, clarify and hand over these evidences to relevant practitioners (30). The major findings of the reviewed papers with respect to evidence-based decision making and decision support system are presented in Table 1.

\section{Knowledge management tools in healthcare}

The amount of information and knowledge processing requirement in today's medicine is huge. In this work, the tools addressed focused on IT tools that support management of knowledge because tools that facilitate the capture and distribution of clinical knowledge become vital (31). Different IT artifacts which are known to support the creation, storage, retrieval, transfer and application of knowledge include data management and learning tools; knowledge repositories; databases; electronic bulletin boards and e-mail services (6). These KM technologies are important components of knowledge management systems and have become central to healthcare. They are considered as one of the strategies to improve quality of service, patient management, research undertaking and identification of effective interventions (32). For example, a knowledge sharing practice at United Nations Population Fund (UNFPA), via knowledge assets development system (KADS), which is a pilot project that UNFPA experimented on knowledge transfer and capture is a good strategy to be adopted. Technology plays a pivotal role in $\mathrm{KM}$ in facilitating knowledge flow through its life cycle and is realized by the implementation of knowledge management system (KMS) because it provides a technical foundation that facilitates KMS implementation (4). The contribution of technology in medical science for the development of healthcare is manifold, of which tools used for diagnostics of normal versus disease status of a patient can be mentioned (5) due to the 
Table 1: Key findings on CDSS for evidence-based decision making and quality of care improvement

\begin{tabular}{|c|c|c|c|}
\hline Author(s) & Year & "Methodology/approach & Key findings \\
\hline Katzan et al & 2011 & $\begin{array}{l}\text { Developing knowledge } \\
\text { program (KP) by } \\
\text { capitalizing on EHR } \\
\text { features }\end{array}$ & $\begin{array}{l}\text { KP based on the use of core EHR features was } \\
\text { designed and evaluated and it was found that web- } \\
\text { based and data quality is central for its success }\end{array}$ \\
\hline $\begin{array}{l}\text { Hongsermeier } \\
\text { et al }\end{array}$ & 2011 & $\begin{array}{l}\text { Developing a legal } \\
\text { framework for sharing } \\
\text { of knowledge and } \\
\text { services }\end{array}$ & $\begin{array}{l}\text { Three legal agreements were developed and the best } \\
\text { practices for knowledge representation and } \\
\text { specification of knowledge content formats is defined } \\
\text { for web based KM portal }\end{array}$ \\
\hline Malmberg et al & 2012 & Literature review & $\begin{array}{l}\text { EHR application can improve KM on HIV. However, } \\
\text { security and privacy issue is a challenge towards full } \\
\text { adoption of HER }\end{array}$ \\
\hline Lapaige & 2009 & $\begin{array}{l}\text { Analysis and framework } \\
\text { development for EBMP }\end{array}$ & $\begin{array}{l}\text { Answer to the "why" and "what" evidence-based } \\
\text { decision making was provided by developing a frame } \\
\text { work }\end{array}$ \\
\hline Kothari et al & 2011 & Systematic review & $\begin{array}{l}\text { Since } \mathrm{KM} \text { is emerging in healthcare sector, lessons can } \\
\text { be learned from the business sector, such as decision } \\
\text { support at critical times }\end{array}$ \\
\hline Sittig et al & 2011 & Survey & $\begin{array}{l}\text { Commercially available tools, similar to internally } \\
\text { developed once, are capable to provide clinical } \\
\text { decision support interventions to clinicians and } \\
\text { perform all key KM functions identified }\end{array}$ \\
\hline Lobach et al & 2012 & Literature Review & $\begin{array}{l}\text { CDSS and KMS have features to provide support at } \\
\text { the time and location of decision making and } \\
\text { improved quality of care }\end{array}$ \\
\hline Clark et al & 2012 & Systematic review & $\begin{array}{l}\text { In the case of shared decision making, patients should } \\
\text { be given enough time, because patients may have poor } \\
\text { knowledge about the evidences }\end{array}$ \\
\hline $\begin{array}{l}\text { Sandars and } \\
\text { Heller }\end{array}$ & 2006 & $\begin{array}{l}\text { Analysis of various } \\
\text { components of KM }\end{array}$ & $\begin{array}{l}\text { The dissemination of knowledge and applying KM } \\
\text { perspective improve implementation of EBMP }\end{array}$ \\
\hline $\begin{array}{l}\text { Cegarra- } \\
\text { Navarro et al }\end{array}$ & 2013 & $\begin{array}{l}\text { Development of } \\
\text { framework }\end{array}$ & $\begin{array}{l}\text { Using the approaches developed, it is possible to } \\
\text { identify inappropriate or obsolete knowledge and } \\
\text { learn new or modified practices }\end{array}$ \\
\hline $\begin{array}{l}\text { Bordoloi and } \\
\text { Islam }\end{array}$ & 2012 & $\begin{array}{l}\text { Literature review and } \\
\text { case study }\end{array}$ & $\begin{array}{l}\text { KM implementation and complete patient information } \\
\text { improved quality of care }\end{array}$ \\
\hline Boateng & 2010 & Qualitative study & $\begin{array}{l}\text { EBMP is the best approach to ensure effective } \\
\text { healthcare delivery }\end{array}$ \\
\hline $\begin{array}{l}\text { Stiggelbout et } \\
\text { al }\end{array}$ & 2012 & $\begin{array}{l}\text { Analysis of best } \\
\text { practices of decision } \\
\text { making }\end{array}$ & $\begin{array}{l}\text { Implementation of sharing decision making, also by } \\
\text { involving patients may lead to better health outcomes }\end{array}$ \\
\hline
\end{tabular}

fact that, in modern healthcare, a central principle is basing treatment, policy and planning decisions on the best available knowledge, research and evidence to improve quality of care (33). The technologies are so many, some of which are knowledge database, Internet, Intranet, extranet, data warehousing, document/content management, decision support system and artificial intelligence. A study by Finkelstein et al (34) focused on the impact of health IT application on improving

DOI: http://dx.doi.org/10.4314/ejhs.v27i5.13 
shared decision making, clinical decision aids, shared decision tools, tele-monitoring system by measuring outcomes such as healthcare choices, satisfaction with decisions, decision conflicts and satisfaction with providers. The finding of a study by these authors showed that the overall health IT application improved patient communication with providers and patient knowledge levels. Technological solutions improve efficient and effective retrieval of knowledge. Codification improves interaction of individual knowledge. However, the bulkiness of published materials is causing difficulty to access (28). The solution is building a centralized knowledge repository (33). Knowledge exchange portals are emerging web tools that facilitate $\mathrm{KM}$ in public health and a platform for providing integrated access to relevant contents and resources. Such portals can be a one-stop shopping for accessing public health programs, interventions and policies (35). Moreover, the portals support knowledge access by providing an online registry of knowledge translation tools and methods as well as demographic data for informed decision making (33). These portals can have design features that enable integrated access to relevant content and resources in one location, sharing and distributing of the required information and bring people together for knowledge exchange. The next generation $\mathrm{KM}$ features anticipated are multiple representation of same piece of knowledge, associative representation strategy and highly reusable components (31).

KM tools for public health are systematic reviews and meta-analyses and can be powerful tools to inform and influence public health policy and practice decisions (28). A good example is the website developed for evidence-based medical practices to provide easily accessible source of published, reliable, up-to-date review to decision makers with options to enhance their critical appraisal skills. A question-answer system developed to support EBMP, a widely accepted paradigm for medical practice being built on knowledge extractors, can automatically identify these elements in MEDLINE abstracts (24). The knowledge-rich features of the system can be combined with simple statistically derived features to build a good outcome classifier. Besides, the work demonstrated that the principle of EBMP can be computationally captured and implemented. Various KM tools utilized in healthcare in order to improve quality of care are presented in Table 2.

III. Opportunities and barriers of KM implementation and tools in healthcare: Today's dynamic changes and invention of technologies in ICT are a big opportunity to improve quality of patient care if fully exploited. However, there are numerous barriers that inhibit or limit informed decision-making in healthcare and thus unprecedented strategies and approaches are needed to overcome. Some of these barriers are presented below.

A. Barriers: Some of the challenges reported in many of the studies reviewed in the present work are infrastructure (technological) constraints, lack of motivation of employees to share knowledge $(12,15,33)$, system unreliability, lack of senior management support, organizational politics patients' privacy issues $(12,33)$, reluctance of clinicians to use ICT tools on daily basis-mainly due to lack of time (5)-, lack of attention to results and use of evidence, lack of incentives for documentation and dissemination, limited document and use of good practices, inadequate awareness about KM systems (16), expensive initial investment, poor quality of patient data or information $(18,30,34)$, inequity in status among practitioners (i.e., inhibitor of knowledge sharing), organizational culture, missing a centralized knowledge-base system and lack of trust $(19,36)$. With respect to EBMP, the existing challenges include lack of fund to implement evidence-based medicine, limited access to modern technologies and up-to-date medical research, the complexity of shared decision making $(14,27)$, perception of low expectation to bring change in target audience, lack of communication between researchers and policy makers, lack of applied research $(29,33)$, difficulty of locating specific information, poor interface usability and problems with access to the health IT applications $(28,34)$.

DOI: http://dx.doi.org/10.4314/ejhs.v27i5.13 
Table 2: KM Tools vs. the future of informed decision making in healthcare in a quest for the provision of quality care

\begin{tabular}{|c|c|c|c|}
\hline Author(s) & Year & Methodology/approach & Key findings \\
\hline Hulse et al & 2012 & Case study & $\begin{array}{l}\text { Knowledge repository (KR) at Intermountain } \\
\text { Healthcare is huge and though the usage is } \\
\text { increasing }\end{array}$ \\
\hline Dobbins et al & 2010 & $\begin{array}{l}\text { Usage analysis of a } \\
\text { website }\end{array}$ & $\begin{array}{l}\text { The level of evidence.ca website usage by public } \\
\text { health decision makers and of the registered users } \\
\text { is encouraging }\end{array}$ \\
\hline Sittig et al & 2010 & Survey & $\begin{array}{l}\text { Tools and techniques that need to be given } \\
\text { priority were identified for successful clinical } \\
\text { decision support development }\end{array}$ \\
\hline Butler et al & 2014 & $\begin{array}{l}\text { Qualitative study and } \\
\text { literature search }\end{array}$ & $\begin{array}{l}\text { Numerous decision aid tools are available for } \\
\text { advanced care planning, but most are not open } \\
\text { source }\end{array}$ \\
\hline Finkelstein et al & 2013 & Systematic review & $\begin{array}{l}\text { Health IT has positive impact on patient-centered } \\
\text { care outcomes }\end{array}$ \\
\hline Cabitza and Simone & 2012 & Web-based survey & $\begin{array}{l}\text { Collective consultation via online platform } \\
\text { enable patients to consult more than one } \\
\text { physician }\end{array}$ \\
\hline $\begin{array}{l}\text { Cegarra-Navarro et } \\
\text { al }\end{array}$ & 2012 & Empirical investigation & $\begin{array}{l}\text { The relationship between organizational learning } \\
\text { and patient e-knowledge can be mediated by } \\
\text { telemedicine technologies }\end{array}$ \\
\hline Dixon et al & 2009 & $\begin{array}{l}\text { Website for knowledge } \\
\text { sharing }\end{array}$ & $\begin{array}{l}\text { Knowledge is codified and stored on the Web in } \\
\text { the knowledge library and applied when the need } \\
\text { arises }\end{array}$ \\
\hline Seto et al & 2011 & Focus group discussion & $\begin{array}{l}\text { KM implementation and also boundary spanning } \\
\text { are encouraged to bring about best strategy for } \\
\text { adaptability and flexibility in KM process }\end{array}$ \\
\hline Deve\&Hapanyengwi & 2014 & $\begin{array}{l}\text { Research findings } \\
\text { analysis }\end{array}$ & Generic KMS architecture was proposed \\
\hline $\begin{array}{l}\text { Cegarra-Navarro et } \\
\text { al }\end{array}$ & 2011 & Qualitative study & $\begin{array}{l}\text { Three models were developed for HHU, namely } \\
\text { control model, conceptual learning model and } \\
\text { operational learning model }\end{array}$ \\
\hline $\begin{array}{l}\text { Demner-Fushman } \\
\text { and Lin }\end{array}$ & 2007 & $\begin{array}{l}\text { Developing algorithm to } \\
\text { extract knowledge }\end{array}$ & $\begin{array}{l}\text { Clinical question-answering system was } \\
\text { developed with knowledge-based and statistical } \\
\text { techniques for EBMP purpose }\end{array}$ \\
\hline Chen et al & 2012 & $\begin{array}{l}\text { Analyzing smart homes } \\
\text { and daily living } \\
\text { activities }\end{array}$ & $\begin{array}{l}\text { System architecture for the knowledge-driven } \\
\text { activity recognition in smart home was proposed } \\
\text { and evaluated }\end{array}$ \\
\hline $\begin{array}{l}\text { Paroutis and Al } \\
\text { Saleh }\end{array}$ & 2009 & Case study & $\begin{array}{l}\text { Knowledge sharing determinants were identified } \\
\text { to be technological, organizational and individual }\end{array}$ \\
\hline Siemsen et al & 2008 & Database development & $\begin{array}{l}\text { Models for knowledge-sharing behavior among } \\
\text { employees was developed and tested }\end{array}$ \\
\hline
\end{tabular}

B. Opportunities: Even though there are a number of challenges which limit the

DOI: http://dx.doi.org/10.4314/ejhs.v27i5.13 
implementation of KM in healthcare as mentioned above, there are opportunities which can transform healthcare by improving the quality of care for patients if seized. The vital opportunities that most of the reviewed papers addressed are presented as follows.

i. Advances in health information and communication technology: The know-how of how to motivate employees to share the knowledge they possess, i.e., the tacit knowledge is vital, because it is very difficult to externalize and share this knowledge type. Nowadays, there exist interactive $\mathrm{KM}$ technologies and their importance for knowledge sharing is emphasized. The most recent ones are blogs, wikis and social media, known as Web 2.0 technologies (36). Some of the reasons for the willingness of health professionals to share their knowledge include effective communication, managing personal knowledge, generating discussion about new concepts or ideas, finding answers to particular problems, staying informed about the latest news and activities of fellow colleagues, receiving desired help and feedback, increasing one's social network, building a level of credibility (37), satisfaction in helping others and passion about some topics.

On the other hand, it is reported that organizational culture affects adoption of new tools of KM perceived benefit of using Web 2.0 technologies (36). These authors opined that rewards or incentives are very psychological in nature and not tangible or monetary. This study also indicated that the key determinants identified are outcome expectations, perceived organizational or management support and trust. It is asserted that the top management should take active leading role in introducing Web 2.0 technologies. Moreover, training and appropriate reward system, such as recognition and praise, should be in place (1). For example, to impact healthcare delivery in the USA, the national resource center has chosen to use a combination of codification and collaboration of ICT and also a variety of formal and informal techniques as part of its strategy of knowledge sharing, among others the us of Web 2.0 technologies (38). Besides, the traditional approach was used to managing the knowledge. In general, advances in technology at present, and inevitably in future, can bring about the best settings whereby patients could get the best possible healthcare services.

ii. Clinical decision support system: The efforts to improve healthcare quality and value play a critical role for meaningful use of Clinical Decision Support System (CDSS) and Knowledge Management System (KMS), tools that selectively provide relevant information as per the circumstance but require human interpretation (39). Examples of such tools are 'Infobutton', an information retrieval tools that help clinicians in the search and retrieval of a specific knowledge, which is an online health knowledge resources being integrated into Electronic Health Record (HER) system (40). KMS supports decision making in any care situation by providing a range of strategies and resources to create represents and distribute knowledge to be practiced by human beings $(2,39)$. Besides healthcare improvement, CDSS and KMS lower the costs required $(17,18)$. According to Lobach et al (39), the factors associated with successful CDSS/KMS implementation are, among others, automatic provision of decision support as part of clinical work flow, provision of decision support at the point of care, provision of recommendation rather than just assessment, integrating with charting or order entry system to support workflow integration, justification of decision support via provision of research evidence for EBMP, user involvement in development process and provision of decision support results to patients and providers. Clinical decision supports can significantly improve quality and safety of healthcare, especially when delivered at the point of care, being aided by EHR system (2).

iii. Electronic health record systems: Developments in electronic health record (EHR) systems focus on providing data for research and patient care as well as prioritizing healthcare providers' resources. The primary goal for EHR systems and related technologies should be to facilitate $\mathrm{KM}$ for improving individual and 
community health. KM in public health is becoming quite interesting for public health officials recently due to its ability to capture knowledge to ensure public health preparedness, managing information more effectively, enabling public health workers to collaborate in a virtual environment and improving effectiveness of resource utilization (41). The fact that EHR systems, being an essential instrument in integrating clinical and public health data system, should be known so that public health authorities will have reliable, real-time data to support health policy decision for better and safer care. Moreover, these authors argued that EHR system is a must have tool for public health officials to improve treatment, care and prevention of disease such HIV/AIDS and its diagnosis.

A similar study indicated that if a well designed system coupled with the key sociotechnical concepts required for safe and effective EHR implementation and use is in place, the anticipated healthcare delivery process is not far from being a reality (42). The need for and use of collaborative clinical $\mathrm{KM}$ tools and techniques to manage clinical decision support content was often overlooked in the past (43). However, the need to develop high quality evidence-based CDS intervention makes the use of Internet-based, collaborative clinical KM tools mandatory. Accordingly, four tools were identified (43). They are: i) External repository of clinical content with web-based viewed, ii) Online, collaborative, interactive, intranet-based tool to facilitate content development (use of Web 2.0); iii) Enterprisewide tool to maintain controlled clinical terminology (such as SNOMED for problem, LOINC for laboratory tests and ICD-9 for billing); and iv) Tools for CDS users to provide feedback regarding specific CDS interventions, a simple online feedback gathering method. These authors opined that there is a need to develop and refine understanding, implementation and use of advanced clinical KM capabilities to speed up the program in the area of CDS.

iv. Communities of practice: Communities of practice $(\mathrm{CoP})$ are becoming popular within health sector from the time when identified as a concept for understanding the sharing, management and creation of knowledge. CoP is used as a vehicle for translation of new health knowledge timely by linking researchers, practitioners, policy makers and consumers. It also facilitates timely and relevant exchange of information and/or knowledge. One of the challenges to integrate research evidence into practice is that it involves a complex nature of acquiring, converting and applying mixture of tacit knowledge and explicit knowledge in critical activities. CoP is being used in the health sector to help practitioners make sense of concrete information, such as practice guidelines (44).

The need for timely translation of new health knowledge into practice is becoming increasingly important. Online strategies for health related knowledge translation can act as vehicles to link researchers, practitioners, policy makers and consumers, thereby facilitating timely and relevant exchange of information and also showing the knowledge gap (37). CoPs (virtual communities) are effective and pragmatic ways for health professionals, the general public and other key stakeholders to interact and share knowledge. Due to expensive initial investment $(18,30,34)$ for the development of full-fledged $\mathrm{KM}$ and its implementation, online $\mathrm{KM}$ strategies help to facilitate health related knowledge translation as it is viewed as an inexpensive, efficient and accessible means to provide support not only to healthcare professionals, but also to patients (37). The fact that such online forums are marked by high degrees of collegiality, sharing of time and resources, interactive and progressive problem solving should be underlined. CoPs are a key component of KM. There is an ever increasing need for healthcare decision-making based on the best possible evidence as it ensures effectiveness and efficiency. Therefore, the distribution of knowledge, i.e., providing the right knowledge at the right time is not an option but mandatory (45). Thus, it should be appropriately stored and applied for informed decision making.

v. Advanced care planning: Advanced care planning (ACP) is a preferred setting for future care of patients when illness or injury prevents adequate communication because it helps patients to assess various care options (13). There are

DOI: http://dx.doi.org/10.4314/ejhs.v27i5.13 
numbers of decision aids available for the purpose, even though most are not open sources. Decision aids tend to be developed for disease-specific conditions because narrower decision choices have a great potential to be taped and popularized to transform healthcare service delivery. Well communicated performances using advanced tools help doctors feel assured and comfortable about ethics of providing or withholding treatments that affects survival. In general, the current situation of limited application due to the barriers mentioned earlier, reflection and boundary spanning is encouraged to optimize the best strategy for adaptability and flexibility in KM implementation because boundary spanners facilitate collaborations that help to lessen risk by bringing individuals with varied knowledge and expertise together, and as a consequence the quality of outputs become better and better (46).

\section{DISCUSSION}

Advances in ICT have greatly contributed to knowledge sharing because knowledge can reach the receiver instantly without need to travel to acquire it, rather just a click away if the technological infrastructure is provided. Online knowledge transfer or knowledge exchange portal is a key facilitator of efficient and timely exchange of knowledge as well as knowledge generation and dissemination $(35,37)$. The finding of this review showed that communities of practice play a pivotal role for managing knowledge flow and improves organizations' performances (44). Because such a practice is used as a vehicle for translation of new health knowledge timely by linking researchers, practitioners, policy makers and consumers. It also facilitate timely and relevant exchange of information and knowledge. Community of practice is gaining attention, and because of its nature, i.e., a free will to share knowledge with a given group, it motivates the participants to know more in order to share more. Accordingly, it is possible to predict that it will be one of the best and widely utilized tools of KM in the future to bring all the stakeholders in knowledge intensive sectors such as healthcare.
The three pillars of knowledge sharing are people, processes and technology. These pillars are inter-connected like, the "host-pathogenenvironment interaction" for a disease to occur. Similarly, knowledge sharing is influenced by people, process and technology (47). Thus, for knowledge flow, there is a need for the right balance among these three pillars of knowledge sharing (5).

Knowledge flow is also made possible via virtual communication, which is a recent development in healthcare delivery. In this way, especially people with disability can get healthcare services by being at their homes, which avoids or minimizes transporting them to hospitals or healthcare facilities. Moreover, one of the big concern in many countries today is the rise in the numbers of aging population, a group that needs intensive care. Virtual communication and HHU can thus be the best solution to provide the necessary healthcare services for elderly people because, like people with disability, frequent visit to health facilities can worsen their health situation besides transportation costs. Therefore, ICT based health services and systems, which is a real-time continuous activity also known as smart home (21), is unprecedented in providing better healthcare delivery. With respect to the EBMP, currently, the concepts of knowledge and evidence have received much attention (23), and it is thus not an option but a must for health professionals to remain competent. To do so, continuous learning and training are important.

In today's health care, the amount of information and knowledge processing requirement is so overwhelming because huge data and information are gathered from every healthcare service provider every single day. Hence, KM tools that facilitate capture and distribution of clinical knowledge become vital, especially for healthcare organizations that champion distribution of their best practices to care for their patients (31). The availability of multiple KM technologies, applications and utilizations are issues that need to be addressed accordingly by respective healthcare organizations. Two main aspects that have to be 
looked into are the knowledge of the employees to utilize the tools and the issue of initial investment. Since installation and maintenance demand big finance, a given organization has to make sure that the process is successful and meets the goal it is intended for. It is utmost importance that the top management unconditionally support the initiative and the full implementation of KM (48). As to the problem of the use of the tools, continuous training should be provided for the employees until they can fully make use of it without seeking assistance. In general, KM implementation and complete patient information (1) by using systems such as EHR improve quality of care for patients and are prospects for healthcare sector.

Lack of motivation of employees to share knowledge is one of the barriers to implementation of $\mathrm{KM}(12,15,33)$. Knowledge sharing provides a connection between people and organization and also creation, dissemination, collaboration, innovation and acquisition of knowledge. Thus, knowledge sharing has an important influence in KM implementation (47). The reason is that even if a state-of-the-art technology is available, it is of no value if employees are not ready to share their knowledge. The underlining reason for knowledge hoarding is lack of awareness and problem of trust due to fear of loss of recognition ones the knowledge they possess is captured and coded. This issue is supported by other studies $(48,49)$. Therefore, there should be the right policy in place to guarantee physicians and convince them that knowledge sharing is all about the patients they are laboring hard to save by improving quality of care to be provided. Moreover, physicians should be given incentives for their time to use the system. This is because time is the most constraining factor for them, a barrier that is emphasized in other studies $(49,50)$. It is obvious that healthcare is not about few individuals or limited to a single organization; rather, it is wide in scope because various stakeholders should involve. The findings of this review showed that there exist lack of communication between policy makers and researchers and also lack of applied research $(29,33)$. However, it is crucial that all are in harmony for a better outcome. Thus, policy makers are expected to give due attention to the research outputs, and researchers should concentrate on applied research to tackle priority problems and provide sustainable solution that improves quality of care.

The existing opportunities to implement KM in healthcare, specifically the KM tools, deserve attention. Numbers of opportunities are reported in the articles reviewed for the present review work. Web 2.0 technologies are among the advances in health ICT (36). These technologies are very interactive, most importantly initiated and managed by volunteers. There are numbers of reasons for professionals to use such tools, the main ones being effective communication, managing personal knowledge, generating discussion about new concepts or ideas, finding answers to particular problems, staying informed about latest news and activities of fellow colleagues, increasing one's social network and building a level of credibility (37). Some of the tools of Web 2.0 are blogs, wikis and the ever increasing social Media. Social Media are especially gaining great attention in every day lives of almost all professionals of any sector who have access to Internet. Accordingly, it is expected to play more roles in healthcare in the future. Other opportunities include clinical decision support system (40), electronic health record system (43), community of practices (44) and advanced care management (13). In order to realize a full-fledged implementation of $\mathrm{KM}$ in healthcare, all concerned bodies, among others, policy makers, researchers, health professionals and healthcare providers need to come together and play their part to seize the opportunities and improve healthcare quality.

In conclusion, in the present review work, the implementation of KM in healthcare, KM tools in healthcare and the available opportunities and also the barriers were identified as the main theme and providing the right knowledge at the right time, i.e., at the point of decision making by implementing KM in healthcare is paramount. To do so, using appropriate tool to manage knowledge and user-friendly system is a requirement as it can significantly improve the quality and safety of care provided for patients 
both at hospital and home settings. At present and evidently in the future, evidence-based medical practice is not an option, but mandatory due to the fact that evidence-based medical practice, i.e., applying the best medical practices to treat and care for patients is the way forward for healthcare sector, which is especially very important for developing countries. However, this can be applied successfully if and only if the right system is in place for knowledge management, and thus, it should be given due attention. In order to materialize this, it is vital to make use of the available opportunities such as advances in ICT, clinical decision support systems, electronic health record systems and community of practices.

\section{ACKNOWLEDGEMENT}

The authors would like to thank Dr. Lawerence Abraham Gojeh and Mr. Ahmed Abdulahi for proof reading the manuscript. The authors are also indebted to the Department of Health Information Management, School of Allied Medical Sciences, Tehran University of Medical Sciences for allowing this review work.

\section{REFERENCES}

1. Bordoloi P, Islam N. Knowledge Management practices and healthcare delivery: A contingency framework. The Electronic Journal of Knowledge Management. 2012;10(2):110-20.

2. Hongsermeier $\mathrm{T}$, Maviglia $\mathrm{S}$, Tsurikova $\mathrm{L}$, Bogaty D, Rocha RA, Goldberg $\mathrm{H}$, et al., editors. A legal framework to enable sharing of Clinical Decision Support knowledge and services across institutional boundaries. AMIA Annual Symposium Proceedings; 2011: American Medical Informatics Association.

3. Nonaka I, Takeuchi H, Umemoto K. A theory of organizational knowledge creation. International Journal of Technology Management. 1996;11(78):833-45.

4. Deve T, Hapanyengwi G. Knowledge Management Systems Generic Architectures: Enhancing Uniformity and Inter-Operability of Technological Tools for Knowledge Management. Electronic Journal of Knowledge Management. 2014;12(3).
5. Arntzen-Bechina A, Leguy C. An insight into knowledge flow in biomedical engineering science. The Electronic Journal of Knowledge Management. 2007;5(2):153-60.

6. Butler T, Murphy C. Understanding the design of information technologies for knowledge management in organizations: a pragmatic perspective. Information Systems Journal. 2007;17(2):143-63.

7. C. El Morr, and J. Subercaze, Knowledge management in healthcare. Handbook of Research on Developments in e-Health and Telemedicine: Technological and Social Perspectives, 2010, pp. 490-510.

8. Boateng W. Knowledge Management in Evidence-Based Medical Practice: Does the Patient Matter? Electronic Journal of Knowledge Management. 2010;8(3):281.

9. Kothari A, Hovanec N, Hastie R, Sibbald S. Lessons from the business sector for successful knowledge management in health care: a systematic review. BMC health services research. 2011;11:173.

10. McCormack L, Sheridan S, Lewis M, Boudewyns V, Melvin CL, Kistler C, et al. Communication and dissemination strategies to facilitate the use of health-related evidence. 2013.

11. Green LW, Ottoson JM, Garcia C, Hiatt RA. Diffusion theory and knowledge dissemination, utilization, and integration in public health. Annual review of public health. 2009;30:151-74.

12. Al-Busaidi KA. Knowledge workers' perceptions of potential benefits and challenges of inter-organizational knowledge sharing systems: a Delphi study in the health sector. Knowledge Management Research \& Practice. 2013;12(4):398-408.

13. Butler M, Ratner E, McCreedy E, Shippee N, Kane RL. Decision Aids for Advance Care Planning. 2014.

14. Siemsen E, Roth A, Balasubramanian S. How motivation, opportunity, and ability drive knowledge sharing: The constraining-factor model. Journal of Operations Management. 2008;26(3):426-45.

15. Azan W, Huber Sutter I. Knowledge transfer in post-merger integration management: case study of a multinational healthcare company in 
Greece. Knowledge Management Research \& Practice. 2010;8(4):307-21.

16. Shoo R, Matuku W, Ireri J, Nyagero J, Gatonga $\mathrm{P}$. The place of knowledge management in influencing lasting health change in Africa: an analysis of AMREF's progress. The Pan African medical journal. 2012;13(Suppl 1).

17. Maracine V, Scarlat E, editors. Dynamic Knowledge and Healthcare Knowledge Ecosystems. Proceedings of the 9th European Conference on Knowledge Management; 2008: Academic Conferences Limited.

18. Scarlat E, Maracine V, Nica A. Knowledge management for virtual reality applications in a home rehabilitation virtual network. Electronic Journal of Knowledge Management. 2008;5(3).

19. Cegarra-Navarro J-G, Cepeda-Carrion G, Martínez-Caro E, Salmador-Sánchez MP, editors. How to Create Relational Capital in Hospital-in-the-Home Units. Proceedings of the 11th European Conference of Knowledge Management; 2011: Academic Conferences Limited.

20. Cegarra-Navarro JG, Wensley AKP, Polo MTS. A conceptual framework for unlearning in a homecare setting. Knowledge Management Research \& Practice. 2013;12(4):375-86.

21. Chen L, Nugent CD, Wang H. A knowledgedriven approach to activity recognition in smart homes. Knowledge and Data Engineering, IEEE Transactions on. 2012;24(6):961-74.

22. Cegarra-Navarro J-G, Sánchez ALG, Cegarra JLM. Creating patient e-knowledge for patients through telemedicine technologies $\dagger$. Knowledge Management Research \& Practice. 2012;10(2):153-63.

23. Lapaige V. Evidence-based decision-making within the context of globalization: A "WhyWhat-How" for leaders and managers of health care organizations. Risk management and healthcare policy. 2009;2:35.

24. Demner-Fushman D, Lin J. Answering clinical questions with knowledge-based and statistical techniques. Computational Linguistics. 2007;33(1):63-103.

25. Cabitza F, Simone C. Investigating the role of a Web-based tool to promote collective knowledge in medical communities. Knowledge Management Research \& Practice. 2012;10(4):392-404.
26. Stiggelbout AM, Van der Weijden $T$, De Wit MP, Frosch D, Legare F, Montori VM, et al. Shared decision making: really putting patients at the centre of healthcare. Boimedical journal. 2012;344:e256.

27. Clark AM, Dryden D, Hartling L. Systematic Review of Decision Tools and Their Suitability for Patient-Centered Decision making Regarding Electronic Cardiac Devices. 2012.

28. Dobbins M, DeCorby K, Robeson P, Husson H, Tirilis D, Greco L. A knowledge management tool for public health: health-evidence.ca. $B M C$ public health. 2010;10:496.

29. Nedjat S, Gholami J, Yazdizadeh B, Nedjat S, Maleki K, Majdzadeh R. Research's Practice and Barriers of Knowledge Translation in Iran. Iranian journal of public health. 2014;43(7):968.

30. Cases M, Furlong LI, Albanell J, Altman RB, Bellazzi R, Boyer S, et al. Improving data and knowledge management to better integrate health care and research. Journal of internal medicine. 2013;274(4):321-8.

31. Hulse NC, Galland J, Borsato EP, editors. Evolution in Clinical Knowledge Management Strategy at Intermountain Healthcare. AMIA Annual Symposium Proceedings; 2012: American Medical Informatics Association.

32. Katzan I, Speck M, Dopler C, Urchek J, Bielawski K, Dunphy C, et al., editors. The Knowledge Program: an innovative, comprehensive electronic data capture system and warehouse. AMIA Annual Symposium Proceedings; 2011: American Medical Informatics Association.

33. Pentland D, Forsyth K, Maciver D, Walsh M, Murray R, Irvine L. Enabling integrated knowledge acquisition and management in health care teams. Knowledge Management Research \& Practice. 2013;12(4):362-74.

34. Finkelstein J, Knight A, Marinopoulos S, Gibbons C, Berger Z, Aboumatar $\mathrm{H}$, et al. Enabling patient-centered care through health information technology. Bethesda MD: Agency for Healthcare Research and Quality (US); 2012.(Evidence Reports/Technology Assessments, No. 206). 2013.

35. Quinn E, Huckel-Schneider C, Campbell D, Seale H, Milat AJ. How can knowledge exchange portals assist in knowledge 
management for evidence-informed decision making in public health? BMC public health. 2014;14(1):443.

36. Paroutis S, Al Saleh A. Determinants of knowledge sharing using Web 2.0 technologies. Journal of Knowledge Management. 2009;13(4):52-63.

37. Mairs K, McNeil H, McLeod J, Prorok JC, Stolee P. Online strategies to facilitate healthrelated knowledge transfer: a systematic search and review. Health information and libraries journal. 2013;30(4):261-77.

38. Dixon BE, McGowan JJ, Cravens GD. Knowledge sharing using codification and collaboration technologies to improve health care: lessons from the public sector. Knowledge Management Research Practice. 2009;7(3):24959.

39. Lobach D, Sanders GD, Bright TJ, Wong A, Dhurjati R, Bristow E, et al. Enabling health care decisionmaking through clinical decision support and knowledge management. 2012.

40. Del Fiol G, Cimino JJ, Maviglia SM, Strasberg HR, Jackson BR, Hulse NC, editors. A LargeScale Knowledge Management Method Based on the Analysis of the Use of Online Knowledge Resources. AMIA Annual Symposium Proceedings; 2010: American Medical Informatics Association.

41. Malmberg ED, Phan TM, Harmon G, Nauert RF. Improving HIV/AIDS Knowledge Management Using EHRs. Online journal of public health informatics. 2012;4(3).

42. Sittig DF, Wright A, Meltzer S, Simonaitis L, Evans RS, Nichol WP, et al. Comparison of clinical knowledge management capabilities of commercially-available and leading internallydeveloped electronic health records. $B M C$ medical informatics and decision making. 2011;11:13.

43. Sittig DF, Wright A, Simonaitis L, Carpenter JD, Allen GO, Doebbeling BN, et al. The state of the art in clinical knowledge management: an inventory of tools and techniques. International journal of medical informatics. 2010;79(1):4457.

44. Li LC, Grimshaw JM, Nielsen C, Judd M, Coyte PC, Graham ID. Use of communities of practice in business and health care sectors: a systematic review. Implementation science : IS. 2009;4:27.

45. Sandars J, Heller R. Improving the implementation of evidence-based practice: a knowledge management perspective. Journal of evaluation in clinical practice. 2006;12(3):3416.

46. Seto I, Arkison B, Williams K. Knowledge management in a small knowledge intensive organisation: research design process at the Cochrane Child Health Field. Knowledge Management Research \& Practice. 2011;9(4):378-84.

47. Rodriguez E, Edwards J. People, technology, processes and risk knowledge sharing. Electronic journal of knowledge management. 2010;8(1):139-50.

48. Ismail Al-Alawi A, Yousif Al-Marzooqi N, Fraidoon Mohammed Y. Organizational culture and knowledge sharing: critical success factors. Journal of knowledge management. 2007;11(2):22-42.

49. Wai Ling C, Sandhu MS, Kishore Jain K. Knowledge sharing in an American multinational company based in Malaysia. Journal of Workplace Learning. 2009;21(2):125-42.

50. Karamitri I, Talias MA, Bellali T. Knowledge management practices in healthcare settings: a systematic review. The International journal of health planning and management. 2015. 